\section{Is there any effect of ESG scores on portfolio performance? Evidence from Europe and Turkey}

Effect of socially responsible investment

Emre Zehir

Department Business Administration, İstanbul Kültür University, Istanbul, Turkey, and

Asli Aybars

Department of Business Administration, Marmara University, Istanbul, Turkey
Received 2 September 2020 Revised 18 September 2020 Accepted 22 September 2020

\begin{abstract}
Purpose - The purpose of this paper is to examine the performance of portfolios that are constructed based on environmental, social and governance (ESG) scores and consist of stocks located in Europe and Turkey.

Design/methodology/approach - In order to form the portfolios, firstly all stocks are ranked in a descending way based on ESG-based (ESG, environmental, social and governance) scores, separately. Then, $10 \%$ of stocks with the highest scores are included in the "Top" portfolio and $10 \%$ of stocks with the lowest scores are included in "Bottom" portfolio and totally performance of eight portfolios are investigated. Finally, capital asset pricing model (CAPM) and Fama-French three-factor model are employed as performance measurement benchmarks.

Findings - Results obtained from CAPM regression show that using ESG-based scores two portfolios underperform the market index. The results of the three-factor model provide that performances of Bottom ESG and Bottom GOV portfolios outperform the market excess return by $0.57 \%$ and $0.53 \%$. The overall findings of this paper indicate that there is no relationship between socially responsible investment (SRI) and portfolio performance. These findings are in line with the efficient market hypothesis which indicates all information is reflected in prices.

Originality/value - The aim of the study is to provide insight on the question of "whether SRI has any effect on the portfolio performance". As far as the literature review is concerned it is seen that this study provide additional insight by utilizing a longer time span together with data from numerous markets.
\end{abstract}

Keywords Socially responsible investment, ESG, Portfolio performance

Paper type Research paper

\section{Introduction}

"Of all the varying concerns that make up the social responsibility component of SRI, the environment is the most fundamental. Philosophically speaking, if the Earth's ability to life is essentially impaired, there seems little point in worrying about the other issues." (Sparkes, 2002).

Investment decisions made by retail or institutional investors start to get complicated nowadays. While trying to maximize financial returns, the problems associated with risk affecting the assets in portfolio should be minimized. Today's complex world changes the terms of risk. Besides the risk that every business carries in itself, other problems like climate change, rising economic inequality, inequal human rights, high tension between countries are some of the other major problems that inject risk into a business.

(C) Emre Zehir and Asl Aybars. Published in Journal of Capital Markets Studies. Published by Emerald Publishing Limited. This article is published under the Creative Commons Attribution (CC BY 4.0) license. Anyone may reproduce, distribute, translate and create derivative works of this article (for both commercial and non-commercial purposes), subject to full attribution to the original publication and authors. The full terms of this license may be seen at http://creativecommons.org/licences/by/4.0/legalcode

This study is extracted from the master thesis prepared in July 2019 at Marmara University. 
JCMS

4,2

In the 21st century, profit maximization cannot be the only goal for the business in a world where global warming is increasing, social and economic inequality gap is growing. Rather than only profit seeking businesses, it is possible to establish a business environment which centers on people, planet and profit (3Ps). 3Ps approach is also known as triple-bottom line (TBL) approach. The term was firstly used in 1994 by John Elkington, who is the founder of the SustainAbility, a British consultancy company that leads its customers to a sustainable economy (Hindle, 2009).

This TBL approach rejects Friedman's 1970 doctrines, which is in line with the traditional approach stating the goal of a business is profit maximization. Elkington (2018) emphasizes that the measurement success of TBL should not only be based on profit or loss, but the wellbeing of billions of people and the health of the planet (Elkington, 2018). This view is the correct one for sustainability and it can be adopted by every business. Furthermore, TBL can also be adopted by the investors and investment companies. The method that takes into account the environmental, social and governance (ESG) issues in investment process is called socially responsible investment (SRI).

One of the main trends in investment area is integrating sustainability issues into the investment process (Blitz and Groot, 2019). For so long, like United Nations (UN), many other organizations are promoting the sustainability in investments. Within the scope of United Nations Development Program's Sustainable Development Goals, SRI is supported under the name of sustainable investment.

Climate change and increasing inequality are the main motivation factors. The upward trend in global warming that starts in the middle of the 20th century is because of the greenhouse effect. Human activities like burning fossil fuels, cutting down the rainforest, etc. are changing the chemistry of green house in the air. Therefore, as a result of global warming, the climate is changing. If combating with the climate change will not be successful, the world will be exposed to greater risk. From the beginning of the industrial revolution, carbon emission has increased substantially. The emission that occurs as a result of burning of fossil fuels is accounting for $80 \%$ of the total emission of human activities (Boden et al., 2010).

Although the Paris Agreement entered into force in 2016, it still seems that the expected targets have not been achieved and the threat of climate change continues. If the current situation continues and the predictions will be true, it will not be clear what kind of world we will live in the future. In such an environment, the area of finance will have a potential to become part of these environmental issues. Especially in the area of investment, SRI will be a good tool for preventing climate change and reducing carbon emissions.

On the other hand, the welfare in the world is not equally distributed among the people. Gender gap has also not been reduced even in 21st century. Since social dimension of SRI includes human rights, community, maintaining diversity and giving equal opportunity to different people, this dimension of SRI aims to contribute to society. In 2016 , while $22 \%$ of the world's income is received by top $1 \%$, only $10 \%$ is received by the bottom $50 \%$. Even though the gap started to diminish after the 2008 financial crisis, it is still very high in 2016 (Alvaredo et al., 2018). Lydenberg et al. (2018) state that institutional investors are beginning to realize that income injustice is one of the most important socioeconomic issues of recent times. It is likely to have a negative impact on the returns of corporate investors' portfolios. It is inevitable that this situation causes instability of the social and financial system. Thus, this instability impacts long-term investment performance (Lydenberg et al., 2018).

Besides the income inequality, gender inequality is another problem in today's world. McKinsey's report in 2015 indicates GDP would be higher by $\$ 12$ tn if the gender inequality gap was closed (McKinsey and Company, 2015). The Global Gender Gap Report 2018 indicates that even though the gap is closing, there is still $38 \%$ gap between the genders. And it may take 202 years to fill this gap (WEF, 2018). This gap seems unfair, yet, investors are starting to realize the power of achieving gender equality. Asset managers and assets owners 
start to take action to fix the gender gap by supporting double-digit vote rights to women (Gorte, 2019).

While all these outcomes seem to be arising for economic and financial reasons, they are essentially ethical. For instance, the empowerment of women in social and business life is the first and foremost ethical issue as much as decreasing environmental effect of businesses. Motivation behind SRI sometimes can be seen as profit, SRI's origin and today's implications; however, are solely based on real problems that have to be solved soon to continue our lives.

\section{Effect of socially responsible investment}

\section{Socially responsible investment}

From the beginning of 1970s a new term, SRI, started to grow as a new concept for the investors. First modern SRI mutual fund, Pax World Fund, was established in 1971 for offering investors alternatives in forming their investments according to personal values. That was the first mutual fund that takes into account social concerns while still offering financial return (Pax World, 2018).

Although the Pax World Fund is accepted as the first modern mutual SRI fund by many academicians and practitioners, history of SRI goes back to ancient times. Preliminary examples of SRI ethical investment can be seen in the history of religion as ethical investment (Renneboog et al., 2007; Sparkes, 2002; Schueth, 2003). Ethical investment has begun to take shape by some religious groups rejecting to invest in funds that benefit from slave trade in the 20 th century. The Pioneer Group that is accepted first socially responsible mutual fund eliminated tobacco, alcohol and gambling firms from the investment universe was established in 1921 (Caplan et al., 2013). Thus, it can be said that the existing point of ethical investment is religion based.

By the 1960s, modern SRI terms start to differ from the ancient religion based ethical investments in terms of individual ethics, environmental and social concerns. Modern SRI forms have updated their point of focus as modifying and improving the behavior of some specific sectors and industries toward social and environmental issues (Louche and Lydenberg, 2006; Schueth, 2003). Social and political campaigns during 1960s,1970s and 1980s like anti-war, anti-racist, environmental protection have made investors aware of the social consequences of their investments.

SRI history in Europe also began with the act of some religion-based activities of those investors who decided to invest in stock exchanges but preferred to avoid investment in sin stocks. However, Louche and Lydenberg (2006) emphasize what differentiates the European SRI market from its American counterparts was the fact that pioneering funds in Europe were more environmental (Louche and Lydenberg, 2006).

Even though ESG issues have been used for more than 50 years in the process of selection, retention and realization of investments; there is still no certain definition of socially responsible investment. Although there is a strong network between organizations, multiple definitions have been used. However, almost all of the definitions used are close to each other as frames despite the presence of a single definition. In addition to the lack of consensus in terms of a single definition, the term used in this paper as SRI can be seen in many forms.

With European Commission's aim to build a clear "sustainable finance" terminology to draw a frame to guide investors in the best way, Eurosif's Board has made a clear and powerful definition that was published it in 2016 (Eurosif, 2016). The definition is as follows;

"Sustainable and responsible investment ("SRI") is a long-term oriented investment approach which integrates ESG factors in the research, analysis and selection process of securities within an investment portfolio. It combines fundamental analysis and engagement with an evaluation of ESG factors in order to better capture long-term returns for investors, and to benefit society by influencing the behaviour of companies" (see Table 1). 
JCMS

4,2

132

Until recently, the SRI approach was being questioned on the basis of whether it is a marginal investment approach or mainstream. The numbers show that the volume of investment made appropriate to SRI criteria has reached to $\$ 30,683 \mathrm{bn}$ in 2018 and; therefore, these types of investments turn to be mainstream (GSIA, 2019).

Global SRI numbers can be observed in many sources like United Nation Principles for Responsible Investment (UNPRI) and the Global Sustainable Investment Alliance (GSIA). UNPRI accounts the total assets of its signatories as responsible investment (PRI, 2018). However, these numbers could not be counted directly as SRI. For this reason, the total value of SRI that is used in this paper is taken from GSIA which is an umbrella organization whose members are the sustainable investment organizations; namely, Eurosif, UKSIF, US SIF, VBDO, JSIF, RIA Canada and RIAA (GSIA, 2019).

Table 2 represents the total value of global sustainable investment in billion US\$. The values that are showed in table are collected manually from the GSIA trend reports. The reports have been published since 2012 .

The numbers demonstrate that growth trend in SRI will continue for the future. Although it is previewed as a marginal investment strategy in its initial period, it has become mainstream. In particular, growth seems to continue with increased awareness of environmental and social issues.

Parallel to the increase in the amount of SRI-related investments, the number of academic studies in the literature on SRI has increased. Capelle-Blancard and Monjon (2012) conduct a research to see the trend in SRI literature over the period of 1982-2019. Using newspapers and academic journals, popularity of the SRI was investigated. The results show that there is an upward trend in the number of SRI-related studies in academic literature. While the first article on SRI was written in 1980s, the number of academic studies was very low for the following two decades. However, they increased in number substantially after year 2000 and nearly 650 research studies were done by academicians in year 2009 (Capelle-Blancard and Monjon, 2012).

Table 1.

Different uses of SRI term among organizations

\begin{tabular}{ll}
\hline Term & Organization \\
\hline Sustainable and responsible investment (SRI) & Eurosif \\
Sustainable and responsible investment (SRI) & UKSIF \\
Responsible investment (RI) & Responsible Investment Association Australasia (RIAA) \\
Responsible investment (RI) & Responsible Investment Association (RIA) \\
Sustainable and responsible investment (SRI) & US SIF \\
Sustainable investment & AfricaSIF \\
Sustainable investment & VBDO \\
Sustainable investment & Japan Sustainable Investment Forum (JSIF) \\
Responsible investment (RI) & UNPRI \\
\hline
\end{tabular}

\begin{tabular}{lrrrr}
\hline & 2012 & 2014 & 2016 & 2018 \\
\hline Europe & $\$ 8,758$ & $\$ 13,608$ & $\$ 12,040$ & $\$ 14,075$ \\
USA & $\$ 3,740$ & $\$ 6,572$ & $\$ 8,723$ & $\$ 11,995$ \\
Canada & $\$ 589$ & $\$ 945$ & $\$ 1,086$ & $\$ 1,699$ \\
Australia/NZ & $\$ 178$ & $\$ 180$ & $\$ 516$ & $\$ 734$ \\
Asia & $\$ 64$ & - & $\$ 52$ & - \\
Japan & $\$ 10$ & - & $\$ 474$ & $\$ 2,180$ \\
Africa & $\$ 229$ & $\$ 21,358$ & $\$ 22,890$ & $\$ 30,683$ \\
Total & $\$ 13,568$ & & &
\end{tabular}


The early studies indicate that the main motivations of SR investors are personal values like ethics and environmental concerns rather than financial performance (Renneboog et al., 2011). However, when it has turned to mainstream, financial performance appears as another important reason for SRI. Amel-Zadeh and Serafeim (2018) develop a survey to understand the motivation behind the use of ESG information among the investors. The results show that financial reasons are the main motivations for use of ESG information rather than ethical concerns (Amel-Zadeh and Serafeim, 2018).

Since the main motivations of SR investors turned into the financial performance, many researchers have investigated the financial performance of SRI in that whether it produces abnormal returns or not. The results can basically be divided into three groups; the studies that assert positive effects of SRI on financial performance, the studies that assert no effects of SRI on financial performance and the studies that assert negative effects of SRI on financial performance. The positive relationship could be seen as the "doing good while doing well" hypothesis. This view asserts that the performance of high-rated stocks outperforms the lowrated stocks or market portfolios. The third one suggests the "doing good but not well". This means that the low-rated stocks or market portfolios generate superior return than high-rated portfolios.

One of the earliest studies in SRI literature that questioned financial performance is done by Hamilton et al. (1993). The paper examines the performance of 32 SRI funds and 320 nonSRI funds which are randomly selected the during the period of 1981-1990. When the financial performance according to history of the funds is investigated, it is seen that the 17 SRI funds that are established before 1985 have higher alpha values with $-0.06 \%$ in comparison to 170 conventional funds that are established before 1985 with an alpha value of $-0.14 \%$. On the other hand, 15 SRI funds that are established after 1985 have an average monthly alpha of $-0.28 \%$. This is low when compared to 150 conventional counterparts which have the average monthly alpha of $-0.04 \%$. It is worth to mention that the alpha values for both SRI and conventional funds are not significant. This means there is no effect of SRI on financial performance.

Similar to Hamilton et al. (1993), Bauer et al. (2007), make a comparison between the Canadian SRI funds and non-SRI funds in the period of 1994-2003. capital asset pricing model (CAPM) and Carhart (1997) four factor model are used for performance evaluation. The results of the regression models show significant underperformance for both SRI and non-SRI funds. Besides using the past performance of SRI funds, some researchers build up portfolios with the stocks. For instance, Mollet and Ziegler (2014) constructed three different portfolios which are named "Sustainability leaders", "MSCI sustainability leaders" and "Other MSCI firms". These portfolios are built up separately for both the US and European market over the period of 1998-2009. Findings show insignificant abnormal return as the supporter of the efficient market hypothesis (EMH) that emphasizes all available information is correctly priced by the market and SRI has no effect on portfolio performance (Mollet and Ziegler, 2014).

One of the most comprehensive studies investigating the SRI is conducted by Auer and Schuhmacher (2016). The paper displays the results from three different regions: the AsiaPacific region, the US and Europe. Three regions, four ESG criteria, five different cut-off rates that are $5 \%, 10 \%, 15 \%, 20 \%, 25 \%$ and five sectors are used for the portfolio construction procedure. As a total, 300 portfolios are built up with the best performer of each being the cutoff level. This procedure is also applied for the worst performer of each cut-off level and a total of 600 best and worst performing portfolios are obtained. The performance evaluation results indicate that only 18 of 60 high-rated portfolios outperform their low-rated counterparts at $5 \%$ cut-off rate. However, this result is insignificant. The overall results of the paper display that regardless of any region, ESG criteria or industry, the high-rated and low-rated portfolios do not provide extra risk adjusted returns (Auer and Schuhmacher, 2016). 
JCMS

4,2

134

Contrary to papers which find out that there is no relation between SRI and financial performance, Diltz (1995) shows that portfolios constructed by focusing on the environmental performance of stocks produce positive significant alphas where Jensen's alpha is used as the performance indicator. In line with the Diltz (1995), Derwall et al. (2005) indicate that considering environmental criteria in the investment process could improve portfolio performance. Kempf and Osthoff (2007) investigate SRI effects on the performance of portfolios that consist of S\&P 500 and DS 400 companies between the years 1992 and 2004. Different screening strategies and long-short strategy are applied to measure their effects. Findings suggest that by applying long-short strategy, investors can earn extra abnormal returns. In addition to this, best-in class or positive screening can be followed by investors. However, negative screening is not suggested to investors. As an overall suggestion, authors indicate the importance of using past SRI ratings for future investment decision (Kempf and Osthoff, 2007).

Similar outperformance results are documented by Statman and Glushkov (2009), who investigate the performance of stocks that have social responsibility scores in the S\&P 500 and DS 400 between the period of 1992 and 2007 using the KLD Research \& Analytics database. The aim of the study is answering whether socially responsible stocks outperform the conventional ones. The results of study show that socially responsible portfolios have an advantage against the conventional ones (Statman and Glushkov, 2009).

Auer (2016) is another example of doing good while doing well hypothesis. The study examines whether SRI adds value on returns in the European market by forming the SRI stock portfolio with stocks traded in the STOXX 600 market index between the period of 2004 and 2012. By utilizing different cut-off levels $(5 \%, 10 \%, 15 \%$ and $20 \%)$ and excluding stocks with the worst scores a total of 17 portfolios are formed. The findings show that performance of portfolios based on the environmental and social scores are not providing statistically significant returns. On the other hand, portfolios based on aggregate ESG score perform better than the passive market benchmark. The author concludes the study with the notion of "European stock market can do well while doing good" (Auer, 2016).

Alessandrini and Jondeau (2019) provide evidence on the firms which are included into MSCI All Countries World Index. The study covers the period between January 2007 and December 2018. ESG screening and smart beta strategies are utilized as portfolio construction methods. The results indicate that both passive ESG strategy, which holds portfolios unchanged until new scores are published, and smart beta strategy produce abnormal returns (Alessandrini and Jondeau, 2019).

\section{Data and methodolgy}

The data used in the study, both ESG data and Stock Market data, which covers the period between 2004 and 2018, are obtained from Thomson Reuters Eikon (Nowadays known as Refinitiv) data terminal. While getting stock price data, "adjusted monthly closing prices" are selected. Since majority of the stocks are located in Eurozone all the stock data are obtained in Euro currency.

Forming portfolios based on ESG scores to measure the effect of ESG scores on portfolio performance is a widely used technique in SRI literature. Constructing ESG portfolios in this study is undertaken to measure the impact of ESG scores on portfolio performance that consists of companies in Europe and Turkey between the years 2004 and 2018.

Since Thomson Reuters publishes ESG scores annually, portfolios in this paper have been created annually. Portfolios are revised each time new scores are published. For the portfolios in year $t$, scores of $t-1$ is used. For each $t$ year, scores of $t-1$ year is ranked in a descending way. After ranking companies based on scores, following the Kempf and Osthoff (2007), 10\% of stocks with the highest scores are included in the "Top" portfolio and $10 \%$ of stocks with the lowest scores are included in "Bottom" portfolio. This method is employed for the ESG, 
Environmental (ENV), Social (SOC) and Governance (GOV) scores, as well. Top and Bottom portfolios are left unchanged until new scores are published.

To test Fama and French (1993) three factor model, SMB and HML portfolios have to be constructed. Following their seminal work, which is named as "Common Risk Factors in the Return on Stocks and Bonds", six different portfolios (S/L, S/M, S/H, B/L, B/M, B/H) are constructed in this paper to obtain SMB and HML factors. These six portfolios are formed with the utilization of size and book to market $(\mathrm{B} / \mathrm{M})$ ratios of stocks.

In the first place, all stocks are sorted by size at the end of year $t-1$. Mean value of the sample is used to divide the sample into two: Small stocks and Big stocks, respectively. Stocks, whose market capitilization is above the mean, are grouped as big stocks (B) and those below the mean are considered as small stocks (S). Secondly, B/M ratios are employed to rank stocks in a descending way to obtain high stocks $(\mathrm{H})$, medium stocks $(\mathrm{M})$ and low stocks (L). The first $30 \%$ of stocks are labeled as $\mathrm{H}$, the next $40 \%$ are labeled as $\mathrm{M}$ and the bottom $30 \%$ are labeled as L. This process is applied for each $t$ year during the period of 2004 and 2018. After the above stated process, the intersection of $\mathrm{S}$ stocks and $\mathrm{H}$ stocks are included in $\mathrm{S} / \mathrm{H}$. This methodology is applied for all intersections.

SMBs are calculated as simple average of small portfolios minus simple average of big portfolios. Eqn 1 shows the formulation of SMB below:

$$
\mathrm{SMB}=\frac{\mathrm{SH}+\mathrm{SM}+\mathrm{SL}}{3}-\frac{\mathrm{BH}+\mathrm{BM}+\mathrm{BL}}{3}
$$

The calculation of HML follows the same methodology of the portfolio formation process utilized in SMB. Intersections of high stocks and big stocks, for instance are included in to $\mathrm{BH}$ portfolio. This method was applied for all intersections.

$$
\mathrm{HML}=\frac{\mathrm{HS}+\mathrm{HB}}{2}-\frac{\mathrm{LS}+\mathrm{LB}}{2}
$$

All portfolios are constructed as equally weighted with all stocks in the portfolios having the same weight. Plyakha et al. (2012) find that equal-weighted portfolios have higher risk than price- and value-weighted portfolios in terms of alpha, Sharpe ratio and mean return. Furthermore, they state that the total return of equal-weighted portfolios outperform the others as a reward of risk. On the other hand, an article published in 2010 on Financial Times (FT); which is one of the main newspapers in this array of literature followed by both academicians and practitioners; report that equal-weighted portfolios perform better (Ferguson and Schofield, 2010).

Performance evaluation of the portfolios are made by using two benchmarks: CAPM regression and Fama-French three factor regression. Besides this, the Sharpe ratio $(\widehat{\mathrm{SR}})$ of portfolios are calculated. Initially, the return of portfolios is annualized to start the evaluation steps. The annualization is made according to following equation;

$$
r_{A}=\left(1+r_{i}\right)^{12}-1
$$

where; $r_{A}$ is annualized monthly excess return, $r_{i}$ is the monthly excess return of portfolio $i$.

Firstly, $\widehat{\mathrm{SR}}$ of portfolios are calculated. $\widehat{\mathrm{SR}}$ quantify the risk-return tradeoff. While measuring $\widehat{\mathrm{SR}}$, Jobson and Kroki (1981) is followed as in the below equation;

$$
\widehat{\mathrm{SR}}=\frac{\widehat{\mu}}{\widehat{\sigma}}
$$

Where; $\widehat{\mu}$ is mean excess return of portfolios, $\widehat{\sigma}$ is standard deviation of excess return of portfolio. 
JCMS

4,2

136

Calculation process of $\widehat{\mathrm{SR}}$ is completed after the annualization of the Sharpe ratio in that $\widehat{\mathrm{SR}}$ is annualized by multiplying $\widehat{\mathrm{SR}}$ with the $\sqrt{12}$.

While testing the performance of any portfolio, the literature uses some techniques. In ESG literature, CAPM is a widely used technique as a performance benchmark. Besides CAPM, multifactor models like Fama and French (1993), three-factor model and Carhart (1997) four-factor model are also used. Accordingly, CAPM and Fama-French three-factor model are employed as performance benchmarks in this paper. After calculating $\widehat{\mathrm{SR}}, \mathrm{CAPM}$ is tested where market premium (excess return on market) is the only explanatory variable.

$$
r_{t}=\alpha+\beta r_{m, t}+\varepsilon_{t}
$$

where; $r_{t}$ is the monthly excess return of portfolio at time $t, \alpha$ is the abnormal return, $r_{m}$ is the monthly risk premium at time $t$ (excess return of market portfolio), $\varepsilon_{t}$ is the error term at time $t$.

For testing Fama and French (1993), the following regression is employed.

$$
r_{t}=\alpha+\beta r_{m, t}+\beta_{\mathrm{SMB}} \mathrm{SMB}_{t}+\beta_{\mathrm{HML}} \mathrm{HML}_{t}+\varepsilon_{t}
$$

where; $r_{t}$ is the monthly excess return of portfolio at time $t, \alpha$ is the abnormal return, $r_{m}$ is the monthly risk premium at time $t$ (excess return of market portfolio), $\mathrm{SMB}_{t}$ is the difference between the small and big stocks at time $t, \mathrm{HML}_{t}$ is the difference between the high and low stocks at time $t$, and $\varepsilon_{t}$ is the error term at time $t$.

To give a general insight on characteristics of ESG, ENV, SOC and GOV portfolios, some general statistics are calculated. Table 3 gives information on annualized excess returns, median values, maximum and minimum annualized excess returns, standard deviations of portfolios. The annualized mean excess returns of Top and Bottom ESG portfolios is 9.5\% and $14.43 \%$, respectively. On the other hand, the highest annualized mean excess return is obtained from the Bottom ESG portfolio. The standard deviations of portfolios are very close to each other. As a risk indicator for portfolio comparison, standard deviation values show that Top ESG portfolio is the riskiest one while Bottom SOC portfolio has the lowest risk. Maximum and minimum values on Table 3 represent the highest annualized return and lowest annualized mean return of portfolios.

Maximum and minimum values demonstrate that returns on portfolios are volatile. For example, return series of Bottom ESG portfolio shows that the maximum annualized excess return of portfolio is $395 \%$ while the minimum is $-86 \%$. SRs of the portfolios are negative for four of the portfolios. This means that the mean of monthly excess return is negative for that four portfolios and these portfolios underperform the risk-free rate. Negative values for the SR do not provide meaningful results. Top SOC portfolio is found to be the best performer for the positive values.

The data used in the analyses section of this paper has the properties of time series data. The time series data can commonly have unit root. For this reason, the test of whether series

Table 3.

Characteristics of portfolios

\begin{tabular}{lccccr}
\hline & Mean & Maximum & Minimum & Std. dev. & \multicolumn{1}{c}{ SR } \\
\hline ESG $_{\text {Top }}$ & 0.0956 & 1.9135 & -0.8477 & 0.0463 & -0.2172 \\
ENV $_{\text {Top }}$ & 0.1358 & 2.2435 & -0.8346 & 0.0446 & 0.0499 \\
SOC $_{\text {Top }}$ & 0.1279 & 2.1107 & -0.8384 & 0.0421 & 0.1353 \\
GOV $_{\text {Top }}$ & 0.0871 & 1.5649 & -0.8452 & 0.0454 & -0.2316 \\
ESG $_{\text {Bottom }}$ & 0.1443 & 3.9553 & -0.8694 & 0.0460 & 0.0535 \\
ENV $_{\text {Bottom }}$ & 0.1114 & 2.2434 & -0.8430 & 0.0440 & -0.1551 \\
SOC $_{\text {Bottom }}$ & 0.1055 & 1.9229 & -0.8629 & 0.0420 & -0.4594 \\
GOV $_{\text {Bottom }}$ & 0.1368 & 1.7481 & -0.8217 & 0.0435 & 0.0070 \\
\hline
\end{tabular}


have unit root is a widely used technique for time series econometrics. Therefore, unit root tests are estimated to check the stationarity of the series. To be precise, augmented DickeyFuller (ADF) test, which is one of the most popular and easy to apply tests, and PhilipsPerron (PP) test, which is more comprehensive than ADF, are conducted for that purpose (Wooldridge, 2009; Brooks, 2008). The results for both ADF and PP tests reject the null hypothesis which asserts that series have unit root.

A regression has to produce well-behaved parameter estimates so that statistically correct hypothesis tests for the significance of parameter estimates can be conducted. The so-called well-behaved nature requires no serial correlation and heteroskedasticity of the errors. In order to check possible serial correlation and heteroskedasticity problems, serial correlation LM test and Breusch-Godfrey-Pagan tests are estimated. Results indicate that there is a serial correlation problem for one of the portfolios (Top GOV portfolio) and various other portfolios suffer from heteroskedasticity problem. Therefore, it is decided to report the heteroskedasticity and autocorrelation consistent estimate.

Breusch-Pagan-Godfrey heteroskedasticity test is performed for testing the null hypothesis which asserts homoskedasticity in the residuals of equations. The test results reject the null hypothesis except the top ENV portfolio. This means that errors in the equations do not have constant variance. To overcome the heteroskedasticity problems, the standard errors are corrected with the Newey and West (1987) method.

\section{Results}

The CAPM results show that all portfolios constructed according the different criteria have nearly zero abnormal return. The results from CAPM tests are presented in Table 4. Abnormal return is also insignificant for the portfolios with two exceptions; namely, Top ESG and Top GOV. Top ESG portfolio's alpha value is $-0.46 \%$. The best performer of the eight portfolios is the Bottom GOV portfolio. However, the alpha value for GOV portfolio is insignificant at $0.01,0.05$ and 0.10 significance levels.

The market premium has strong ability to explain the monthly excess returns of portfolios. The $R^{2}$ values that are obtained from the regression results show that portfolio returns can be explained by the market premium factor in the model. The market premium variables, which show systematic risk exposure to the portfolios indicate that all of the portfolios are exposed to high systematic risk. They are significant at 0.01 significance level

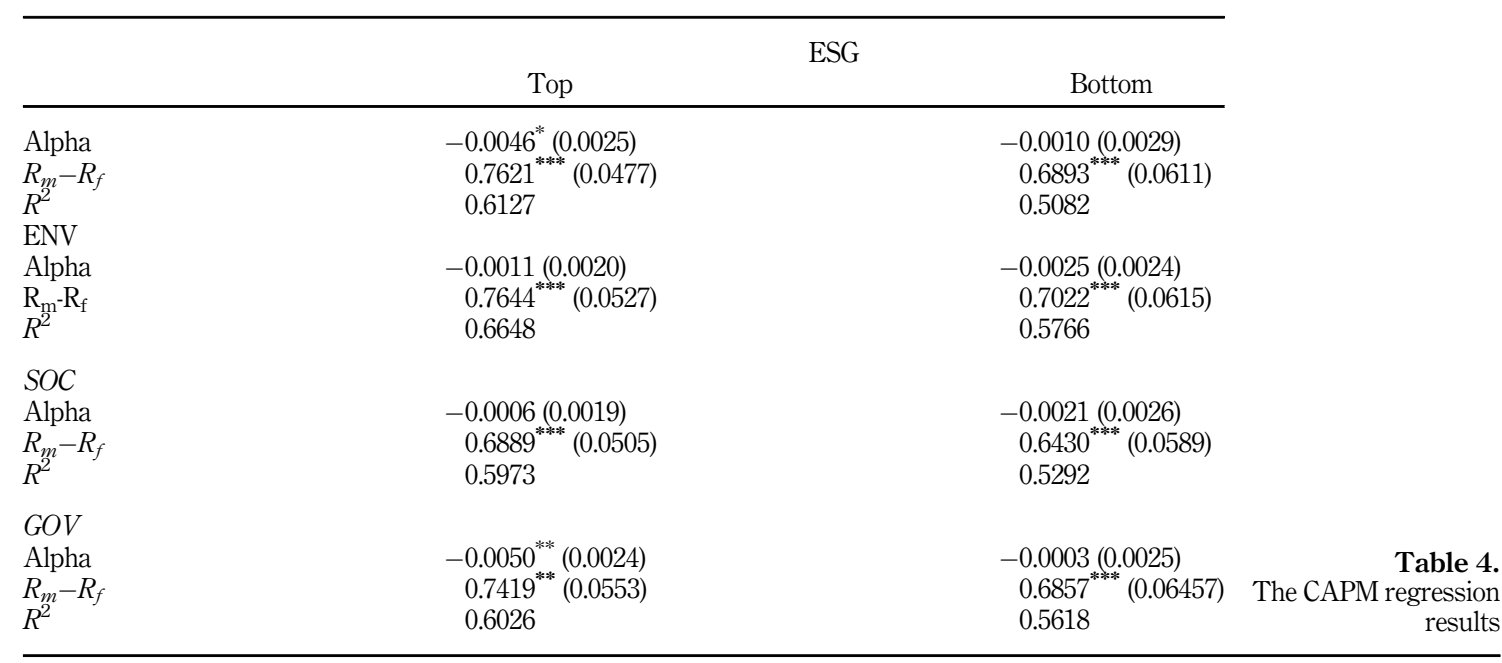

Effect of socially responsible investment 
JCMS

4,2

\section{8}

for seven of the portfolios while it is significant for Top GOV portfolio at 0.05 significance level.

The results for Fama and French (1993) multifactor regression indicate that portfolios constructed based on ESG, ENV, SOC and GOV scores demonstrate nearly zero abnormal return. Results of Fama-French three-factor model are similar with the CAPM on the basis of abnormal returns. The results for each of four score types will be interpreted separately.

Table 5 shows the results for two portfolios constructed according to the ESG scores. The results for the ESG portfolios show that Bottom portfolio has better performance than Top portfolio. While Bottom ESG portfolio produce $0.57 \%$ abnormal return, the alpha value of the Top portfolio is $0.09 \%$ and insignificant. Systematic risk exposure to Bottom portfolio is lower than the Top portfolio. Adding two factors to CAPM, the exposure of systematic risk that portfolios are exposed to decreases. The SMB factor coefficients are positive and significant at 0.05 and 0.01 significance levels for Top and Bottom portfolios, respectively. This means that returns of Top and Bottom portfolios have the same characteristics with $\mathrm{SMB}$ portfolio. The same positive relation is observed between the ESG portfolios and HML portfolio. Factors' ability in explaining portfolio returns are strong with the $R^{2}$ values of 0.65 and 0.60 for Top and Bottom portfolios, respectively.

The results for the ENV portfolios show that portfolios constructed regarding the ENV scores are not able to produce any return above the market. Table 6 shows the Fama and French (1993) three-factor model regression results for the ENV portfolios. The alpha values of portfolios are $0.24 \%$ for Top and $0.23 \%$ for Bottom portfolios. However, the abnormal returns produced by the ENV portfolios are insignificant at all significance levels (0.01, 0.05 and 0.10$)$. The findings for ENV portfolio are in line with the Galema et al. (2008) which shows that performance of portfolios based on ENV criteria are insignificant (Galema et al., 2008). The findings of the analyses are contrary to Derwall et al. (2005), who find that concerning ENV criteria in portfolio formation can add value on portfolio performance (Derwall et al., 2005).

\begin{tabular}{|c|c|c|}
\hline & & \\
\hline & Top & Bottom \\
\hline Alpha & 0.0009 (0.0029) & $0.0057^{*}(0.0032)$ \\
\hline$R_{m}-R_{f}$ & $\begin{array}{l}0.6581^{* * * * *} \\
(0.0623)\end{array}$ & $\begin{array}{l}0.5855^{* * *} \\
(0.0670)\end{array}$ \\
\hline SMB & $0.3006^{* *}(0.1842)$ & $0.6808^{* * * *}(0.1430)$ \\
\hline HML & $0.2051(0.0904)$ & $0.1626^{* * * *}(0.0891)$ \\
\hline$R^{2}$ & 0.6545 & 0.6060 \\
\hline
\end{tabular}

Time series regression results for ESG portfolios

Note(s): ${ }^{* * *} p<0.01 ;{ }^{* *} p<0.05 ;{ }^{*} p<0.10$; Standard errors in parenthesis; The standard errors are fixed with the Newey and West (1987)

\begin{tabular}{lll}
\hline \multicolumn{1}{c}{ Top } & ENV & \multicolumn{1}{c}{ Bottom } \\
\hline Alpha & $0.0024(0.0028)$ & \\
$R_{m}-R_{f}$ & $0.6951^{* * * *}(0.0562)$ & $0.0023(0.0030)$ \\
SMB & $0.1273(0.1300)$ & $0.6428^{* * * *}(0.0582)$ \\
HML & $0.1448^{* * * * *}(0.0625)$ & $0.7246^{* * * *}(0.1526)$ \\
$R^{2}$ & 0.6806 & $0.0560(0.0562)$ \\
& & 0.6692
\end{tabular}

Table 6. results for ENV portfolios

Note(s): ${ }^{* * * *} p<0.01 ;{ }^{* * *} p<0.05 ;{ }^{*} p<0.10$; Standard errors in parenthesis; The standard errors are fixed with the Newey and West (1987) 
On the other hand, Top portfolio is more exposed to systematic risk than the Bottom portfolio. The beta values are 0.60 and 0.58 for Top and Bottom portfolios, respectively. The factors included in model are helping to explain the returns of portfolios. While the SMB factor is explaining the performance of Top ENV portfolio weakly, it helps for explaining the returns of Bottom portfolio. However, HML factor is explaining both Top and Bottom portfolios poorly. $R^{2}$ values obtained from the regression results are providing that returns of two ENV portfolios can be explained by factors included in the model.

The results related with performances of SOC portfolios also show that social scores have no effect on portfolio performance. The performances of two SOC portfolios are almost the same with the alpha values of $0.39 \%$ and $0.15 \%$. The abnormal returns are insignificant at all significance levels (0.01, 0.05 and 0.10). The results are in line with the Auer (2016) who indicates that social scores neither add value on portfolio performance nor destroy it (Auer, 2016). The beta values for both SOC portfolios are positive and both portfolios are exposed to systematic risk at same levels. SMB factor has explanatory power for Bottom portfolio, while it is weak for Top portfolio. On the other hand, while HML is significant at $0.01 \%$ for the Top portfolio, it is insignificant at $0.01,0.05$ and 0.10 significance levels for the Bottom. The explanatory power of the model for the SOC portfolios are strong with the $R^{2}$ values 0.62 and 0.57 for Top and Bottom portfolios, respectively (Table 7).

Table 8 represents the regression results for GOV portfolios. The abnormal returns of portfolios indicate that while the Bottom GOV portfolio has $0.53 \%$ abnormal return with a significance level at 0.10 , Top portfolio underperforms the Bottom with $0.41 \%$ insignificant abnormal return. Similarly, Statman and Glushkov (2009) indicate that portfolios with high governmental scores underperform those with low scores (Statman and Glushkov, 2009). The systematic risk exposure for the portfolios are at the same level. SMB factor has strong explanatory power on portfolios and is significant at 0.01 for both portfolios. However, HML factor is weak for the Top and Bottom portfolios. HML is also insignificant for the Bottom one. $R^{2}$ values that are obtained from regression results show that factors included in the model have strong explanatory power on the returns of portfolios.

\begin{tabular}{|c|c|c|}
\hline & \multicolumn{2}{|c|}{ SOC } \\
\hline & Top & Bottom \\
\hline Constant & $0.0039(0.0027)$ & $0.0015(0.0032)$ \\
\hline$R_{m}-R_{f}$ & $0.6024^{* * * * *}(0.0660)$ & $0.5928^{* * * * *}(0.0578)$ \\
\hline SMB & 0.1777 (0.1690) & $0.4447^{* * * *}(0.1546)$ \\
\hline HML & $0.1788^{* * *}(0.0863)$ & $0.0661(0.0678)$ \\
\hline$R^{2}$ & 0.6258 & 0.5719 \\
\hline
\end{tabular}

Note(s): ${ }^{* * *} p<0.01 ; * * 0.05 ; \stackrel{*}{*} p<0.10$; Standard errors in parenthesis; The standard errors are fixed with the Newey and West (1987)

\begin{tabular}{|c|c|c|c|}
\hline & \multicolumn{2}{|c|}{ GOV } & \\
\hline & Top & Bottom & \\
\hline Constant & $0.0041(0.0028)$ & $0.0053^{*}(0.0031)$ & \\
\hline$R_{m}-R_{f}$ & $0.7095^{* * * *}(0.0577)$ & $0.6001^{* * * *}(0.0695)$ & \\
\hline SMB & $0.5659^{* * * *}(0.1583)$ & $0.5777^{* * *}(0.1564)$ & \\
\hline HML & $0.1405^{* *}(0.06775)$ & $0.1323(0.0796)$ & \\
\hline & 0.7754 & 0.6389 & Time series regression \\
\hline \multicolumn{3}{|c|}{$\begin{array}{l}\text { Note(s): }:^{* * * *} p<0.01 ;{ }^{* * *} p<0.05 ;{ }^{*} p<0.10 ; \text { Standard errors in parenthesis; The standard errors are fixed with the } \\
\text { Newey and West }(1987)\end{array}$} & $\begin{array}{r}\text { results for GOV } \\
\text { portfolios }\end{array}$ \\
\hline
\end{tabular}

Note(s): ${ }^{* * *} p<0.01 ; *{ }^{* *} p<0.05 ;{ }^{*} p<0.10$; Standard errors in parenthesis; The standard errors are fixed with the Newey and West (1987)

\section{Effect of socially responsible investment}

139 
JCMS

4,2

140

As a result of Fama-French three factor regression, the portfolios constructed based on different criteria (ESG score, ENV score, SOC score and GOV score) do not outperform the benchmark. The alpha values of Bottom ESG portfolio and Bottom GOV portfolio are positive and significant at 0.10 . The rest are insignificant at all significance levels. The overall result of the tests indicates that using ESG-based scores during the process of selection, retention and realization of investments do not add any additional significant return. These results are in line with the $\mathrm{EMH}$ which indicates all information are reflected in prices and no investor can earn abnormal return by utilizing different techniques. The $R^{2}$ values that are obtained from the regression results vary between 57 and $78 \%$. This means that the factors that are included in the model have strong ability to explain portfolio returns.

\section{Conclusion and further sugestions}

The concept of SRI has been discussed throughout the study in terms of historical development, literature and performance measurement. SRI can be defined as an investment philosophy that takes into consideration ESG-based (ESG, environmental, social and governance) issues. While it is seen as a new strategy, its history goes back to ancient times. In its initial time, SRI was a marginal investment style. Social and environmental incidents during the 1970s and 1980s led investors, who are sensitive to social and environmental issues, to seek new investment strategies that suit their personal values. Especially in 1980s, the number of SRI mutual funds has started to increase. At the same time, empirical studies that investigate the performance of SRI has increased. This paper investigates the performance of SRI by utilizing companies' ESG-based scores in the investment process.

The aim of the study is the provide insight on the question of "whether SRI has any effect on the portfolio performance". The empirical results obtained from the CAPM results shows that performance of Top ESG and Top GOV portfolios underperform the market excess return and the results are statistically significant at 0.10 for Top ESG portfolio and at 0.05 for Top GOV portfolio. For the other six portfolios, the results are statistically insignificant. This means that portfolios based on SRI do not outperform or underperform others.

Since one of the main criticisms against the CAPM is that the single factor is insufficient to explain stock returns, Fama-French three-factor model is also employed in this study to analyze the presence of any abnormal returns. The results of the three-factor model provide that performances of Bottom ESG and Bottom GOV portfolios outperform the market excess return by $0.57 \%$ and $0.53 \%$. The results are statistically significant at 0.10 significance level for both portfolios.

On the other hand, after adding common risk factors that are size and value, systematic risk exposure to portfolios decrease. Besides this, SMB factor has strong ability to explain Bottom portfolios' returns and coefficients are statistically significant at 0.01 . While it is significant for Top ESG and Top GOV portfolios, the explanatory powers are slightly low. HML factor has low explanatory power on the performances of portfolios and it is insignificant for Bottom portfolios.

The overall performances of the eight portfolios that are examined in this paper provide insight on the SRI and performance relationship. The literature has three different views on this relationship. The overall findings of the thesis provide that there is no significant impact of SRI on portfolio performance in the period of 2004 and 2018.

For the further research studies, different trading strategies like long-short strategy can be applied. The long-short strategy means buying a portfolio while selling another. In particular, for the forthcoming studies, which will examine SRI and performance relationship, a strategy of holding a long position on the high-rated portfolios and selling the low-rated portfolios can be developed. 
Besides the above stated strategies, the time span of the study can be divided into subperiods. This can give information about short-term performance of SRI. This type of performance measurement allows to make comparison between the long-term and short-term performance of SRI-based strategies.

Another suggestion is that using ESG data from different data providers can provide an opportunity to make comparison between the performance of portfolios. Since the methodology that data providers use in calculation of ESG scores differ in terms of weight of pillar, reporting frequency, etc., performance of portfolios that are constructed based on different data sources can give different results. Thus, performance comparison between the data providers can be evaluated in future studies.

In addition to the above stated suggestions, models used in the evaluation process can be altered. Since the investment literature suggests that multifactor models have strong ability to explain portfolio returns, using Carhart four-factor model or Fama-French five-factor model would be helpful to gain more insight about the SRI and performance relationship.

\section{References}

Alessandrini, F. and Jondeau, E. (2019), ESG Investing: From Sin Stocks To Smart Beta, Swiss Finance Institute, Geneva.

Alverado, F., Chancel, L., Pikette, T., Saez, E. and Zucman, G. (2018), World Inequality Report-2018: Executive Summary, Berlin.

Amel-Zadeh, A. and Serafeim, G. (2018), "Why and how investors use ESG information: evidence from a global survey", Financial Analysts Journal, Vol. 74 No. 3, pp. 87-103.

Auer, B.R. (2016), "Do socially responsible investment policies add or destroy European stock portfolio value", Journal of Business Ethics, Vol. 135 No. 2, pp. 381-397.

Auer, B.R. and Schuhmacher, F. (2016), "Do socially (ir)responsible investment pay? New evidence from international ESG data", The Quarterly Review of Economics and Finance, Vol. 59, pp. 51-62.

Bauer, R., Derwall, J. and Otten, R. (2007), "The ethical mutual fund performance debate: new evidence from Canada”, Journal of Business Ethics, Vol. 70 No. 2, pp. 111-124.

Blitz, D. and Groot, R. (2019), "Passive investing and sustainability integration are fundamentally irreconcilable investment philosophies", The Journal of Portoflio Management, Vol. 45 No. 4, pp. 7-11, doi: 10.3905/jpm.2019.45.4.007.

Boden, T.A., Andres, R.J. and Marland, G. (2010), Global, Regional, and National Fossil-Fuel CO2 Emissions, Tennessee: Carbon Dioxide Information Analysis Center, Oak Ridge National Laboratory, U.S. Department of Energy.

Brooks, C. (2008), Introductory Econometrics for Finance, Cambridge University Press, New York, NY.

Capelle-Blancard, G. and Monjon, S. (2012), "Trends in the literature on socially responsible investment: looking for the keys under the lamppost", Business Ethics: A European Review, Vol. 21 No. 3, pp. 239-250.

Caplan, L., Griswold, J.S. and Jarvis, W.F. (2013), From SRI to ESG: The Changing World of Responsible Investing, Commonfund Institude, Wilton.

Carhart, M.M. (1997), "On persistence in mutual fund performance", The Journal of Finance, Vol. 52 No. 1 , pp. $57-82$.

Derwall, J., Guenster, N., Bauer, R. and Koedijk, K. (2005), "The eco-efficiency premium puzzle", Financial Analysts Journal, Vol. 61 No. 2, pp. 51-63.

Diltz, J.D. (1995), "Does social screening affect the portfolio performance", Journal of Investing, Vol. 4 No. 1 , pp. $64-69$. 
JCMS

4,2

142

Elkington, J. (2018), 25 Years Ago I Coined the Phrase “Triple Bottom Line.” Here's Why It's Time to Rethink it, [Online] available at: https://hbr.org/2018/06/25-years-ago-i-coined-the-phrase-triplebottom-line-heres-why-im-giving-up-on-it (accessed 18 April 2019).

Eurosif (2016), European SRI Study 2016, Eurosif, Brussels, available at: http:/www.eurosif.org/wpcontent/uploads/2016/11/SRI-study-2016-HR.pdf.

Fama, E.F. and French, K.R. (1993), “Common risk factors in the return on stocks and Bonds”, Journal of Financial Economics, Vol. 33 No. 1, pp. 3-56.

Ferguson, R. and Schofield, D. (2010), Equal weighted portfolios perform better, Financial Times.

Galema, R., Plantinga, A. and Scholtens, B. (2008), "The stocks at stake: return and risk in socially responsible investment", Journal of Banking and Finance, Vol. 32 No. 12, pp. 2646-2654.

Gorte, J. (2019), "Pax world funds”, [Online] available at: https://paxworld.com/the-investment-case-forgender-equality/.

GSIA (2019), 2018 Global Sustainable Investment Review, GSIA.

Hamilton, S., Jo, H. and Statman, M. (1993), "Doing well while doing good? The investment performance of socially responsible mutual funds", Financial Analysts Journal, Vol. 9 No. 6, pp. 62-66.

Hindle, T. (2009), "Triple bottom line”, [Online] available at: https://www.economist.com/news/2009/11/ 17/triple-bottom-line (accessed 10 October 2018).

Jobson, J. and Korkie, B. (1981), "Performance hypothesis testing with the Sharpe and Treynor measures", The Journal of Finance, Vol. 36 No. 4, pp. 889-908.

Kempf, A. and Osthoff, P. (2007), "The effect of socially responsible investing on portfolio performance”, European Financial Management, Vol. 13 No. 5, pp. 908-922.

Louche, C. and Lydenberg, S. (2006), Socially Responsible Investment: Diffirinces Between Europe and United States, Vlerick Leuven Gent Working Paper Series 2006/22, Vlerick Leuven Gent Management School, Gent.

Lydenberg, S., Michael, M., Burckart, W. and Clark, M. (2018), Why and How Investors Can Respond To Income Inequality, UNPRI.

McKinsey and Company (2015), The Power of Parity: How Advancing Women's Equality Can Add \$12 Trillion To Global Growth, McKinsey and Company, London.

Mollet, J.C. and Ziegler, A. (2014), "Socially responsible investing and stock performance: new empirical”, Review of Financial Economics, Vol. 23 No. 4, pp. 208-216.

Newey, W.K. and West, K.D. (1987), "A simple, positive semi-definite, heteroskedasticity and autocorrelation consistent covariance matrix", Econometrica, Vol. 55 No. 3, pp. 703-708.

Pax World (2018), "Pax world history”, [Online] available at: https://paxworld.com/about/history/.

Plyakha, Y., Uppal, R. and Vilkov, G. (2012), "Why does an equal-weighted portfolio outperform valueand price-weighted portfolios?”, available at: SSRN 2724535.

PRI (2018), Principles for Responsible Investment Annual Report 2018.

Renneboog, L., Horst, J.t. and Zhang, C. (2007), Socially Responsible Investments: Methodology, Risk Exposure and Performance, TILEC Discussion Paper No. 2007-013; ECGI - Finance Working Paper No. 175/2007, European Corporate Governance Institute (ECGI), Brussels, 1 June.

Renneboog, L., Horst, J.T. and Zhang, C. (2011), "Is ethical money financially smart? Nonfinancial attributes and money flows of socially responsible investment funds", Journal of Financial Intermediation, Vol. 20 No. 4, pp. 562-588.

Schueth, S. (2003), "Socially responsible inveting in the USA", Journal of Business Ethics, Vol. 43, pp. 189-194.

Sparkes, R. (2002), Socially Responsible Investment: A Global Revolution, John Wiley \& Sons, West Succex. 
Statman, M. and Glushkov, D. (2009), "The wages of social responsibility”, Financial Analysts Journal, Vol. 65 No. 4, pp. 33-46.

WEF, (2018), The Global Gender Gap Report, WEF, Geneva.

Wooldridge, J.M. (2009), Introductory Econometrics A Modern Approach, 4th ed., South-Western Cengage Learning.

\section{Corresponding author}

Emre Zehir can be contacted at: e.zehir@iku.edu.tr

For instructions on how to order reprints of this article, please visit our website: www.emeraldgrouppublishing.com/licensing/reprints.htm Or contact us for further details: permissions@emeraldinsight.com 